\title{
Challenges and Opportunities of Structural Adjustment of Higher Education in China for the Employment Work in Independent Colleges
}

\author{
Ying Tan \\ School of Management, Wuhan Donghu College, Wuhan, 430212, China \\ E-mail:85066405@qq.com
}

Keywords: Independent College; Employment; Higher education

\begin{abstract}
Based on statistical analysis, this paper questions the view of the previous scholars that the structural adjustment of higher education in China has but a negative impact on the employment work of independent colleges. Equipped with a dialectical perspective, it discusses both the challenges and the opportunities afforded by the structural adjustment of China's higher education for the employment work of independent colleges in the country, and on this basis, it presents the corresponding strategies for promoting the employment rate of graduates from independent colleges.
\end{abstract}

\section{Introduction}

Independent colleges, as a new form of higher education in China, are intended to meet the growing needs of the society which is seeing the popularization of higher education. At present, there are 300-plus independent colleges across China, which have become a key supplier of undergraduate education. However, due to their short history, independent colleges understandably meet with many problems, such as in scale of operation, room for development, and mode of talents cultivation. And the touchstone of how well these problems are resolved in independent colleges is the employment of their students after graduation. For this reason, the employment of graduates from independent colleges, like that of students from regular institutions of higher learning, is given serious attention by the society. The following will present a discussion on the impact of the structural adjustment of higher education in China on the employment of graduates from independent colleges.

\section{Connotations of Layer Structure of Higher Education}

The structure of higher education has two aspects, macroscopic and microscopic, and the layer structure of higher education is one part of the macroscopic structure. Also called the horizontal structure of higher education, the layer structure of higher education refers to the constitution of higher education of different levels and requirements and carries the relations and combinations of different levels of higher education, including non-degree diploma education, bachelor's education, master's education, and doctoral education[1].

\section{Adjustment of Layer Structure of Higher Education in China}

A. Trend in Structural Adjustment of Higher Education in China

Since the adoption of the enrollment expansion policy in 1998, the higher education in China has seen tremendous growth. In 2006, the enrollment of bachelor's degree students totals 2,530,854, and this number increases to 2,970,601 in 2008 and 3,566,411 in 2011, which exceeds the enrollment in 2006 by $1,035,557$ or $40.9 \%$. In the meantime, the enrollment of master's degree students has increased from 341,970 to 494,609 in 2011 , also by $44.64 \%$. These statistics point to the rapid, constant change in the structure of higher education in China, which represents a real transition from elite education to mass education.

Table I. Students Enrolled into Different Levels of Programs in Colleges and Universities in China in the Past 6 Years

\begin{tabular}{|c|c|c|c|c|c|c|}
\hline & & & & \multicolumn{3}{|c|}{ Unit: Person } \\
\hline Level $\quad$ Year & 2006 & 2007 & 2008 & 2009 & 2010 & 2011 \\
\hline Doctoral & 55,955 & 58,022 & 59,764 & 61,911 & 63,762 & 65,559 \\
\hline Master's & 341,970 & 360,590 & 386,658 & 449,042 & 474,415 & 494,609 \\
\hline Bachelor's & $2,530,854$ & $2,820,971$ & $2,970,601$ & 326,1081 & $3,512,563$ & $3,566,411$ \\
\hline Non-degree Diploma & $2,929,676$ & $2,838,223$ & $3,106,011$ & $3,133,851$ & $3,104,988$ & $3,248,598$ \\
\hline
\end{tabular}


B. Features of Structural Adjustment of Higher Education in China

From Table I, it can be seen that the enrollment in colleges and universities of China in the past years has been increasing steadily, which is fairly obvious with the higher-level master's degree students and least obvious with the lower-level non-degree diploma students. The growth in the enrollment of bachelor's degree students is the largest, exceeding those of other levels of students both in absolute and relative terms. Clearly, there is a shift in China towards the higher level of education, with the popularization trend of higher education increasingly remarkable, which, of course, is the result of both higher education reform and social \& economic development.

\section{Impact of Structural Adjustment of Higher Education in China on the Employment Work in Independent Colleges}

A. Challenges

1) The rapid growth in undergraduate education in China is bringing difficulties to the employment work in independent colleges which rely heavily on undergraduate education.

On the one hand, the negative influence of the crisis has already been felt in some regions, some industries and some economic fields. Due to the sharp decrease in orders, many companies in China have started to reduce their staff and their recruitment, which exerts mounting pressure on the job market, and fresh graduates are the first to suffer whose job-hunting has become increasingly difficult. On the other hand, with the total number of graduates, especially those holding bachelor's degree, from colleges and universities increasing year by year (Please see Table II), the employment situation for fresh graduates from colleges and universities including independent colleges is worsening. (Please see Fig. 1)

Table II . Statistics of Graduates from Colleges and Universities of China in the Past 6 Years

Unit: Person

\begin{tabular}{|l|l|l|l|l|l|l|}
\hline \multicolumn{1}{r|r|}{ Year } & $\mathbf{2 0 0 6}$ & $\mathbf{2 0 0 7}$ & $\mathbf{2 0 0 8}$ & $\mathbf{2 0 0 9}$ & $\mathbf{2 0 1 0}$ & $\mathbf{2 0 1 1}$ \\
\hline Devel & & & & & \\
& $\begin{array}{l}36,24 \\
7\end{array}$ & $\begin{array}{l}41,46 \\
4\end{array}$ & $\begin{array}{l}43,75 \\
9\end{array}$ & $\begin{array}{l}48,65 \\
8\end{array}$ & $\begin{array}{l}48,98 \\
7\end{array}$ & $\begin{array}{l}50,28 \\
9\end{array}$ \\
\hline Master's & $\begin{array}{l}219,6 \\
55\end{array}$ & $\begin{array}{l}270,3 \\
75\end{array}$ & 301,0 & 322,6 & 334,6 & $\begin{array}{l}379,7 \\
06\end{array}$ \\
\hline $\begin{array}{l}\text { Bachelor' } \\
\text { s }\end{array}$ & $\begin{array}{l}1,726, \\
674\end{array}$ & $\begin{array}{l}1,995, \\
944\end{array}$ & $\begin{array}{l}2,256, \\
783\end{array}$ & $\begin{array}{l}2,455, \\
359\end{array}$ & $\begin{array}{l}2,590, \\
535\end{array}$ & $\begin{array}{l}2,796, \\
229\end{array}$ \\
\hline $\begin{array}{l}\text { Non- } \\
\text { degree } \\
\text { Diploma }\end{array}$ & $\begin{array}{l}2,048, \\
034\end{array}$ & $\begin{array}{l}2,481, \\
963\end{array}$ & $\begin{array}{l}2,862, \\
715\end{array}$ & $\begin{array}{l}2,855, \\
664\end{array}$ & $\begin{array}{l}3,163, \\
710\end{array}$ & $\begin{array}{l}3,285, \\
336\end{array}$ \\
\hline
\end{tabular}

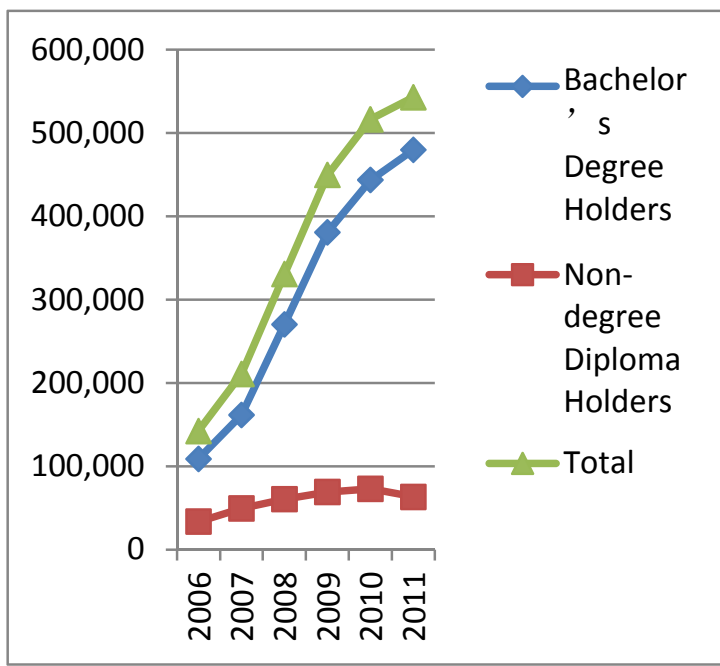

Figure1. Change in the statistics of graduates from independent colleges in china in the past 6 years

b. Source of Data: Statistical Yearbook of Education in China (2010)

(2009) (2008) (2007) (2006);

Summary of Statistics in China in 2012

2) The rapid growth in undergraduate and graduate education has increased the supply-demand contradiction in the human resources market characterized by the shortage of scientific and technological graduates and the redundancy of humanities and social sciences graduates, which means that independent colleges face even a worse situation with its reliance on humanities and social sciences programs.

In the past 6 years, the human resources market in China has seen an abundant supply on the whole, yet the shortage of personnel with professional or technical skills is serious. According to a report by the Chinese Academy of Personnel Science, the supply of personnel with professional or technical skills in 2010 is 40 million, far less than the total demand which is 60 million. In the meantime, the rapid growth in graduate education hasn't changed the disciplinary structure of colleges and universities, which has increased the supply-demand contradiction in the human 
resources market with scientific and technological talents in shortage and humanities and social sciences talents in surplus.

Due to the restraints of material conditions, a human and financial resource, independent colleges in China started with an emphasis on humanities and social sciences programs, this cost less and involves fewer difficulties. This is especially truly of privately-funded independent colleges, which rely almost completely on humanities and social sciences programs [2]. It can be imagined that, in a human resources market where graduates with professional or technical skills are urgently sought for while those with humanities or social sciences background are not popular, independent colleges which depend heavily on humanities and social sciences programs naturally have a bleak prospect with regard to its employment work.

B. Opportunities

With the severe situation of employment, both academic and industrial communities hold that the structural adjustment of higher education in China has made it more difficult for graduates from independent colleges to land on a job and the influence is largely negative. Nevertheless, opportunities often coexist with challenges, and the influence of structural adjustment of higher education in China on the employment of graduates of independent college should be examined with a dialectical perspective. Using statistical methods, this author attempts to discuss the opportunities afforded by the structural adjustment of higher education in China for the employment of graduates from independent colleges. Since independent colleges has become a key supplier of undergraduate education and their graduates, like those from other types of colleges and universities, will finally go to the human resources market for job, this author intends to analyze the correlation between the structural adjustment of higher education and the overall employment rate of undergraduates in China so as to reveal opportunities for independent colleges in context.

Because independent colleges, as a product of the popularization and diversification of higher education in China, has a history of only about 10 years and their graduates first entered the human resources market about 6 years ago, the analysis here will mainly use statistics of higher education and employment rates of undergraduates in China between 2006 and 2011.

1) Correlation between the structural adjustment of higher education and the overall employment rate of undergraduates in China

Since the structural adjustment of higher education mainly finds expression in the change of enrollments and enrollments determine the number of students to graduate, which further influences employment, this author will use statistics in Table II and the employment rates of undergraduate and college students in China 6 months after their graduation (60.37\% in 2006, 87.5\% in 2007, $85.6 \%$ in 2008, $86.6 \%$ in 2009, $89.6 \%$ in 2010, and $90.2 \%$ in 2011[3]) and calculate their correlation by means of SPSS17.0.

a) Overlapping Scatter Diagram

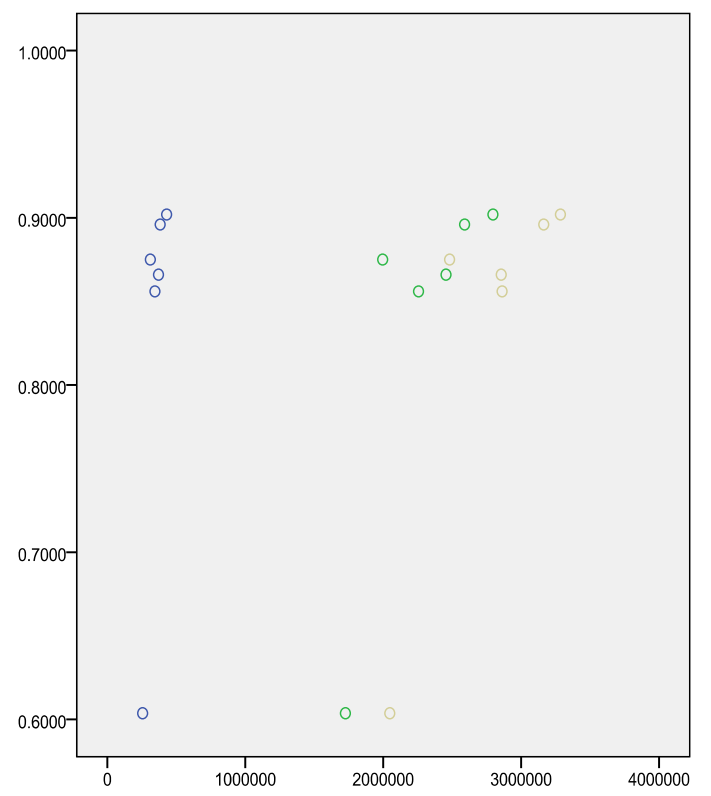

b) Multiple Linear Regression Analysis

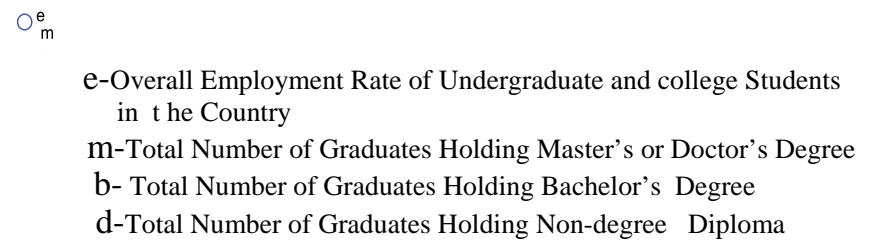

It can be seen from the overlapping scatter diagram that there is a strong correlation between the total number of graduates holding master's or doctor's degree, the total number of graduates holding bachelor's degree and the overall employment rate of undergraduate and college students in the country, and the correlation between the total number of graduates holding non-degree diploma and the overall employment rate of undergraduate and college students in the country is also obvious. 
Now that there is a strong correlation between the total number of graduates holding master's or doctor's degree, the total number of graduates holding bachelor's degree, the total number of graduates holding non-degree diploma and the overall employment rate of undergraduate and college students in the country in the past 6 years, this author will try to investigate the relationship between them, i.e. the pattern of qualitative changes between them, by taking the total number of graduates holding master's or doctor's degree, the total number of graduates holding bachelor's degree, the total number of graduates holding non-degree diploma as the independent variables and the overall employment rate of undergraduate students in China as the dependent variable.

Table IV. Correlations

Table III. Anova ${ }^{b}$

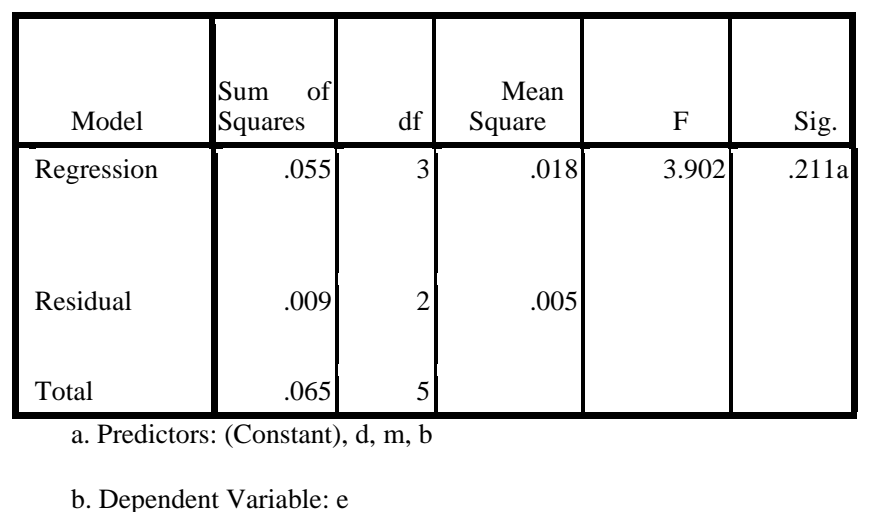

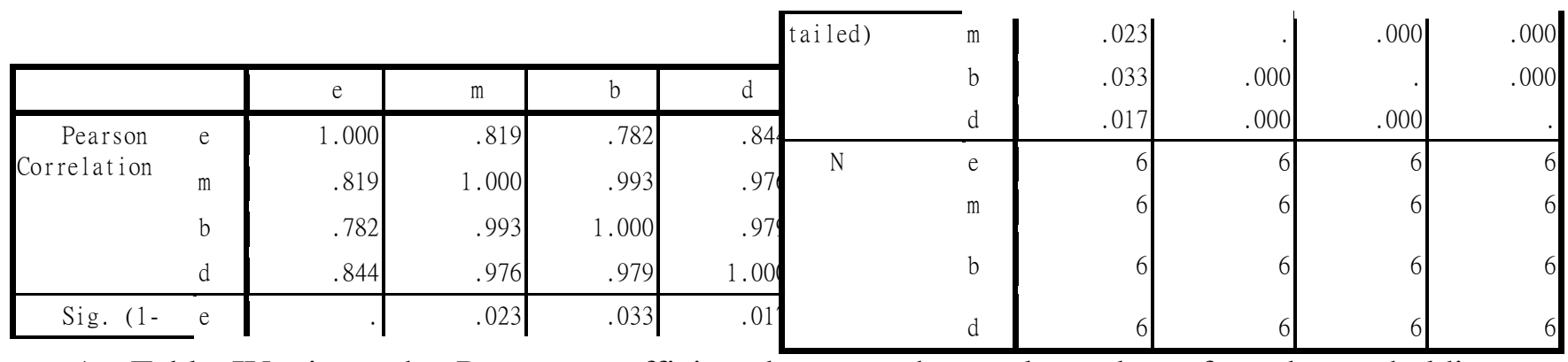

As Table IV gives, the Pearson coefficient between the total number of graduates holding master's or doctor's degree and the overall employment rate is 0.819 , displaying strong positive correlation, that between the total number of graduates holding bachelor's degree and the overall employment rate is 0.782 , displaying significant positive correlation, and that between the total number of graduates holding non-degree diploma and the overall employment rate is 0.844 , displaying strong positive correlation, too. And Table III gives $\mathrm{F}=3.902$ and $\mathrm{P}>0.001$, which indicates that there is no linear regression relationship between the several independent variables and the dependent variable. Because the employment issue of independent colleges has a history of no more than 6 years and statistics that can be used are limited, fitting of the curve model is not practically significant. Therefore, having reached the conclusion that there is no linear regression relationship between the several independent variables and the dependent variable, this author decides not to make non-linear regression analysis.

From the statistical analysis, two conclusions may be obtained: First, the growth in graduate and undergraduate education is a positive factor for the employment rate of undergraduate students. Secondly, on the whole, there is no cause-and-effect relationship between the change in the enrollment for different levels of programs in colleges and universities of China and the employment rate of undergraduate students. In other words, the current situation of employment of undergraduate and college students in China is not caused, or more exactly not directly caused, by the structural adjustment of higher education - There must be other factor or factors in work.

2) Analysis of opportunities for independent colleges

a) Sharing the positive impact with other types of job-hunters 
Now that the growth in graduate and undergraduate education promotes the employment rate of undergraduate students (The next part will explain "why"), undergraduate students from independent colleges will naturally share the positive impact. This conclusion seems more reasonable and convincing when the characteristics of students from independent colleges are considered. Students in independent colleges share two in common: First, most of them are from city; secondly, most of them were born after 1990. Consequently, they are active, creative, capable, flexible, fashionable, having strong personality and wide-ranging interests. They often stand out in varied practical activities. They are more likely to win the favor of the employers who have shifted their emphasis from high grades to experiences and capabilities of the candidate.

b) Searching for and controlling controllable factors, minimizing the negative impact and maximizing the position one.

Now that the current situation of employment of undergraduate students in China is not caused, or more exactly not directly caused, by the structural adjustment of higher education and there are other factor or factors in work, which is given before, it is significant to single out and control the factor or factors, which will help minimize the negative impact of the structural adjustment of higher education and prove to be an opportunity for the graduates from independent colleges.

3) Why the growth in varied levels of higher education has promoted the employment of undergraduate students

Not many years ago, the employers were troubled by not being able to find the right employees and graduates from colleges and universities complained about the difficulty of finding a suitable employer. The structural defect of the higher education resulted in the false impression of talents supply exceeding the demand and structural unemployment was serious. In the past 10 years, the structural adjustment of higher education in China has brought the labor market more talents who hold bachelor's or higher degree. The employers are more likely to find the right employees and optimized match between talents and positions is rendered possible, which promotes employment. Meanwhile, with the growth in higher education, especially in high-level education, graduates at all levels have lowered their expectations and the cases of the job hunter unfit for a higher post yet unwilling to take a lower one have been greatly reduced. This also helps promote employment.

\section{Suggestions for Independent Colleges to Raise the Employment Rate of Their Graduates}

A. Eliminating social prejudices by turning out graduates of strong capabilities

If independent colleges can bring the merits of their students into fully play and develop the practical abilities of their students by introducing more internships and externships into college curriculum, organizing more contests, and offering their students more opportunities of doing research, they will surely turn out graduates of strong capabilities. In this way, they will be able to gradually eliminate social prejudices and create favorable conditions for the job-hunting of their graduates.

B. Competing against others with their strengths instead of their weakness by developing unique specialties

Independent colleges should make full use of the teaching, research and experimental resources of their parent university for the cooperative building of their own disciplines and specialties. At the same time, they should try their utmost to build their own brand specialty and programs by utilizing the academic resources in basic disciplines in their parent university, and compete with other types of colleges and universities with their unique features and strengths.

C. Designing programs and determining teaching content on the basis of social needs with the purpose of serving local economic development

Independent colleges must be clear that their goal is to produce application-oriented graduates of multiple talents for the development of local or regional economy, and since the situation in the market economy changes constantly, independent colleges must have an accurate prediction of the direction of local and regional economic development so that they will never fail to follow the rhythm of the market. They should emphasize the cultivation of techniques and skills of their students, nail down their educational objectives, encourage customized training and combining inschool practice with externship, and determine the content of teaching according to the demand.

D. Developing talents of entrepreneurship 
Faced with severe situation in the labor market, independent colleges should, on the one hand, try to give graduates more guidance regarding employment and on the other, make serious efforts to prepare students as talents of entrepreneurship. As has been said, students in independent colleges have their own advantages. Many of them come from comparatively wealthy families and their parents are either businessmen or entrepreneurs or government employees. Therefore, they have plenty of resources at their disposal if they want to start a business or an enterprise. Independent colleges should, firstly, cultivate their students' entrepreneurship and nurture their interests in business startup. To this end, the traditional teaching approach of spoon-feeding must be discarded; instead, the colleges need to find a way to fire their students' enthusiasm in starting their own enterprises and encourage them to examine study and life from the perspective of business startup.

Secondly, independent colleges need to develop their students' abilities for entrepreneurship. They may open a market on campus for students to exchange second-hand goods, encourage students to open online stores, hold business startup contests, and urge students to take part in various national contests, such as e-business contest, logistic contest, and marketing contest, and turn their achievements into products in the market.

\section{References}

[1] M.Y. Pan, A New Course in Higher Education Studies (Second Edition) , Beijing: Beijing Normal University Press, 2009.

[2] S.L Xu,."Problems with Program Setup in Independent Colleges and Possible Causes”, Chinese College and University Education,vol.6, pp.76-77+86, 2008.

[3] MyCOS Research Institute, Chinese College Graduates’ Employment Annual Report (Blue Book of Employment, 2012, 2011, 2010, 2009.

[4]Development and Planning Department of Ministry of Education, Statistical Yearbook of Education in China, Beijing: People Education Press, pp.4, 2010, 2009, 2008, 2007, 2006

[5] State Statistical Bureau, Summary of Statistics in China in 2012, Beijing: China Statistics Press , pp.165-169,2012 